\title{
A mobilidade pendular na Macrometrópole Paulista: diferenciação e complementaridade socioespacial ${ }^{\star}$
}

\author{
Commuting in the macrometropolis of São Paulo: \\ differentiation and socio-spatial complementariness
}

José Marcos Pinto da Cunha

Sergio Stoco

Ednelson Mariano Dota

Rovena Negreiros

Zoraide Amarante Itapura de Miranda

\section{Resumo}

0 presente estudo tem como principal objetivo realizar um diagnóstico sobre as tendências e características da mobilidade pendular na chamada Macrometrópole Paulista, utilizando as informações disponíveis nos Censo de 2000 e 2010. 0 conhecimento da situação atual e da evolução desse fenômeno pode contribuir significativamente para a avaliação do processo de interação e complementariedade socioespacial que se desenvolve entre as aglomerações urbanas, onde já são claras as novas formas de localização tanto da atividade econômica quando da população em geral. 0 estudo desse fenômeno, portanto, contribui para o diagnóstico do processo de estruturação desses espaços e, sobretudo, para mitigar deficiências existentes em termos de política habitacional, de transportes, de saúde, educação, etc

Palavras-chave: demografia; deslocamentos populacionais; macrometrópole paulista; urbanização; região metropolitana.

\begin{abstract}
The main objective of this article is to make a diagnosis of the trends and characteristics of commuting in the so-called Macrometrópole Paulista (Macrometropolis of São Paulo), using the information available in the 2000 and 2010 Censuses. The knowledge of the current situation and of the evolution of this phenomenon may greatly contribute to the evaluation of the process of socio-spatial interaction and complementariness that develops among urban centers, where the new forms of location both of economic activity and of the population in general are already clear. The study of this phenomenon, therefore, contributes to diagnose the process of structuring of these spaces and, above all, to mitigate deficiencies in housing, transport, health and education policies, among others.
\end{abstract}

Keywords: demography; population mobility; macrometropolis of São Paulo; urbanization; metropolitan region. 


\section{Introdução}

Nos últimos dez anos, enquanto a taxa de crescimento anual da população das regiões metropolitanas paulistas foi de 1,1\%, a taxa de crescimento dos movimentos pendulares entre as regiões que compõem a Macrometrópole Paulista foi de $8,7 \%$ ao ano.

0 fenômeno da mobilidade pendular ${ }^{1}$ constitui um reflexo da diversidade sociodemográfica e espacial existentes nas grandes aglomerações urbanas, em particular aquelas de caráter metropolitano. De fato, esse tipo de movimento, que se caracteriza por sua regularidade (embora possa ser ou não cotidiano), é resultado do descompasso da ocupação dessas regiões em termos demográficos e econômicos, cujos condicionantes têm sido considerados tanto a partir de uma visão macro, em geral ligada ao processo de produção do espaço e localização das atividades produtivas, quanto a elementos microssociais, tais como as novas preferências de moradia, principalmente da população de mais alta renda.

Vários autores têm contribuído para a descrição e diagnóstico desse fenômeno (Aranha, 2005; Oliveira e Oliveira, 2011; Moura et al., 2005; Cunha, 994), uma vez que alguns deles têm ido mais adiante no sentido de buscar explicação para esse tipo de movimento populacional (Ihlanfeldt, 1994; Kain, 1992; Jardim, 2007; Sobreira, 2007; Cunha e Sobreira, 2008; Pereira, 2008; Lobo et al., 2009). 0 presente trabalho aborda o fenômeno da pendularidade a partir de uma visão que extrapola o olhar microrregional da dinâmica intrametropolitana.

É fato que esse tipo de movimentação seja mais intenso e volumoso dentro das aglomerações urbanas, especialmente aquelas de caráter metropolitano. Interessante constatar que, em função das mudanças em nossa sociedade, particularmente a partir dos anos 1990, é possível observar um verdadeiro extravasamento das possibilidades de mobilidade pendular para além das fronteiras regionais, de diferentes recortes espaciais.

A emergência e reconhecimento institucional da Macrometropóle Paulista talvez seja um dos aspectos que melhor retratam essas novas tendências que decorrem de processos estruturais, como a reestruturação produtiva e a desconcentração econômica, com implicações socioespaciais e demográficas importantes. Assim, o aumento da complementariedade econômica e social entre os territórios, mesmo não alterando radicalmente a lógica metropolitana, tem propiciado uma "urbanização dispersa" (Reis Filho, 2006) que, além de outros impactos, acaba incrementando os deslocamentos de pessoas entre regiões de forma cada vez mais intensa.

0 presente ensaio, além de apresentar as principais características da recém-reconhecida Macrometrópole Paulista e discutir algumas contribuições para a compreensão e análise dos movimentos pendulares, concentra-se, sobretudo, em revelar as principais características e tendências desse tipo de deslocamento, ocorrido, ao longo dos anos 2000, entre as quatro Regiões Metropolitanas (RM São Paulo, RM Campinas, RM Baixada Santista e RM Vale do Paraíba e Litoral Norte) que representam a maior parte da população que conforma essa grande área de integração e complementariedade econômica, social, política e de infraestrutura. 


\section{Macrometrópole Paulista: o maior sistema urbano brasileiro}

A Macrometrópole Paulista - MMP configura o sistema urbano mais importante do país. Ocupa 20\% da superfície do estado de São Paulo e concentra municípios situados em um raio aproximado de 200 quilômetros a partir da capital. A articulação e integração são tão intensas entre as cidades desse sistema que seus principais problemas só podem ser resolvidos de maneira integrada. Trata-se do maior e mais complexo sistema de cidades do País, que abrange 173 municípios, quatro Regiões Metropolitanas - São Paulo, Campinas, Baixada Santista e Vale do Paraíba e Litoral Norte, três aglomerações urbanas - Jundiaí, Sorocaba e Piracicaba e duas microrregiões - Bragantina e São Roque (ver Mapa 1) - todas elas com elevada influência do polo principal, o município de São Paulo.

Ainda que sua consolidação tenha ocorrido entre 2000 e 2010, com configurações muito semelhantes da atual, a Macrometrópole tem sido objeto de estudos técnicos desde os anos 1970 (Emplasa, 1992; Emplasa; FSEADE/SEP; 2010). Mas se naquele momento, a unidade regional da Macrometrópole, como era chamada em Souza (1978, p. 25), tinha sua configuração objetivada pela área de influência da indústria e buscava-se um processo de planejamento de descentralização e desconcentração da RM de São Paulo para as cidades médias, hoje, a Macrometrópole Paulista destaca-se pela complementariedade e dinamismo das trocas entre suas regiões componentes.

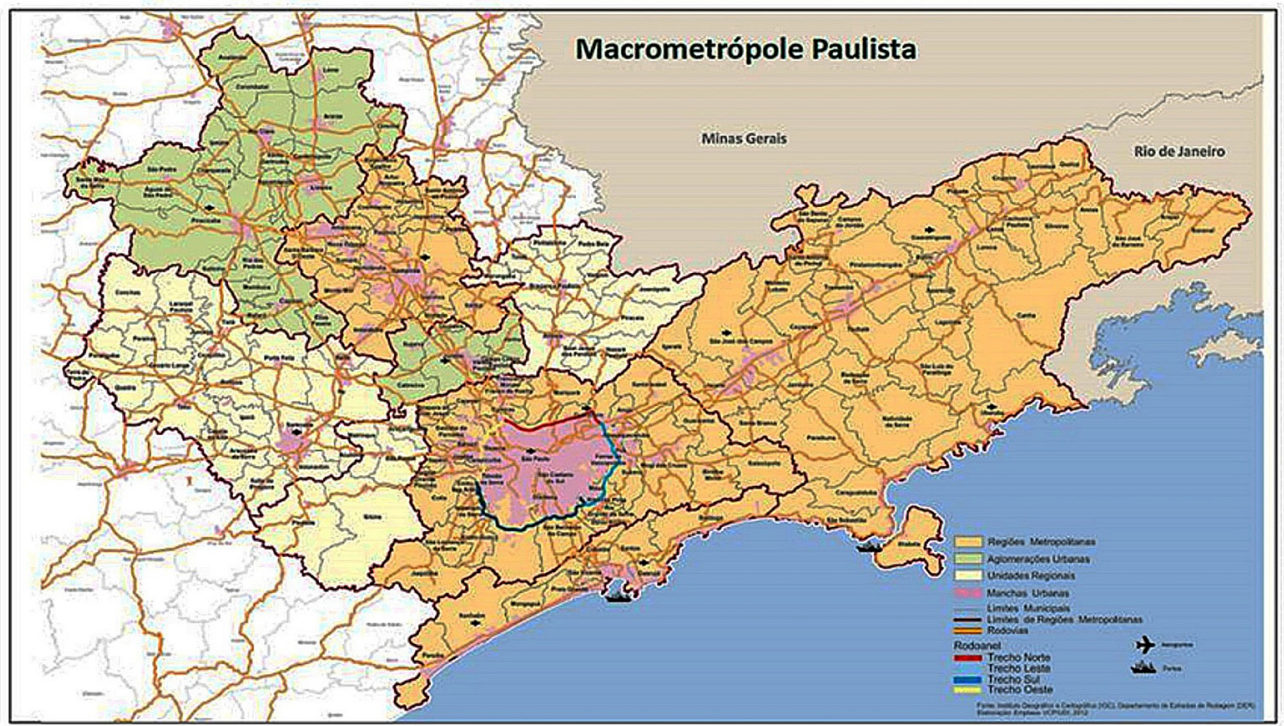

Fonte: Emplasa (2012). 
Nessa região vivem mais de 30 milhões de pessoas, 73\% da população do Estado, gerando uma riqueza equivalente a $83 \%$ do Produto Interno Bruto (PIB) paulista e $28 \%$ do PIB brasileiro (IBGE, 2009). São 50 mil quilômetros quadrados de área urbana que abrigam $50 \%$ da mancha urbanizada do Estado. A Macrometrópole é identificada como um fenômeno urbano-regional complexo, reunindo conjuntos de aglomerações urbanas e centros articulados em rede em um único processo de relações econômico-sociais.

Com relação aos limites territoriais da Macrometrópole ainda existem divergências, uma vez que os recortes propostos em trabaIhos técnicos distintos nem sempre coincidem. Para alguns especialistas, trata-se de um novo desenho urbano ou uma nova escala de metropolização (Moura, 2009; Ribeiro et al., 2012; Meyer e Grostein, 2012).

A Macrometrópole ocupa uma extensa porção da região sudoeste do Estado, com formação associada aos processos de urbanização, interiorização do desenvolvimento econômico e desconcentração produtiva e populacional da Região Metropolitana de São Paulo - RMSP (Negri, 1996; Cano, 1998; Pacheco, 1998).

Sua estrutura econômica, diversificada e complexa, é composta por atividades modernas de alta tecnologia em diversos segmentos econômicos. A maior parte da atividade econômica do Estado se localiza nesse território, sobretudo nos setores industrial e de serviços, cujas maiores contribuições correspondem às metrópoles de São Paulo (RMSP), Campinas (RMC), Vale do Paraíba e Litoral Norte (RMVPLN) e Baixada Santista (RMBS). A concentração econômica é ainda maior que a populacional, liderada pela RMSP com $56 \%$ do
PIB e $48 \%$ da população e, mais distante, pela RMC com $8 \%$ do PIB e $7 \%$ da população. Apenas a RMBS apresenta participação relativa similar entre PIB e população (4\%).

A espacialização da tipologia do PIB dos municípios paulistas, realizado pela Fundação Seade em 2008, contribui para reafirmar a integração e articulação econômica presente nesse território. Dentre os 39 municípios que compõem a RMSP, 19 são "multissetoriais ou de perfil industrial relevante", destacando a presença de atividades industriais e serviços associados nessa região, muitas delas ligadas às demais RMs. Na RMBS, é possível identificar uma continuidade e complementaridade de suas atividades econômicas com a RMSP, com Cubatão, limite com São Bernardo do Campo, classificado como município industrial com relevância, devido à presença do complexo químico-siderúrgico e Guarujá, Santos, São Vicente e Praia Grande - classificados como multissetoriais, como resultado da presença do Porto de Santos na economia regional. $\mathrm{Na}$ RMVPLN, São José dos Campos exerce o papel de polo regional, concentrando mais de $50 \%$ do valor adicionado da indústria e serviços do Vale do Paraíba. Sorocaba concentra mais de $50 \%$ da riqueza da $\mathrm{AU}$, classificada como "industrial com relevância". A AU de Jundiaí teve todos os seus municípios classificados no perfil produtivo industrial com importantes nexos de integração com as regiões vizinhas. Na RMC, Campinas e Hortolândia foram classificados com perfil multissetorial, e os municípios do entorno com perfil industrial. A Macrometrópole conta com uma densa infraestrutura viária e portuária, com intensos fluxos de carga como reflexo das interações para dentro e para fora dessa região. A malha ferroviária é integrada 
por corredores de escoamento de produtos originados em São Paulo e em outros estados com destino ao Porto de Santos, o principal da América Latina, que movimenta $11 \%$ das exportações e $21 \%$ das importações do país. Já no sistema aeroportuário, destacam-se os aeroportos Internacionais de Congonhas (São Paulo), André Franco Montoro (Guarulhos) e Viracopos (Campinas), que exibem os mais expressivos volumes de passageiros e cargas transportadas do País, correspondendo a 54\% do volume da Infraero.

Chama a atenção a movimentação de passageiros que demonstra a grande concentração de fluxos na Macrometrópole, tanto no que se refere às origens (95\%) quanto aos destinos (97\%). A maior parte das viagens tem origem e destino na própria
Macrometrópole (95\%). Os fluxos rodoviários e aeroportuários evidenciam a grande integração e articulação funcional entre os centros urbanos que configuram a Macrometrópole Paulista² (ver Mapa 2).

É interessante notar que as grandes autoestradas que cortam essa região (como a Bandeirantes - ao norte, Airton Sena - ao leste, Castelo Branco, ao oeste - e Imigrantes, ao sul) se configuram em verdadeiras "avenidas" em função do grande fluxo de pessoas, bens e serviços entre as regiões.

As várias regiões componentes da Macrometrópole apresentaram, nas últimas décadas, graus de urbanização superiores a $90 \%$, chegando, em 2010, a 94\%. A mancha urbana principal acompanha os principais eixos viários (ver Mapa 2).

\section{Mapa 2 - Infraestrutura viária e aeroportuária}

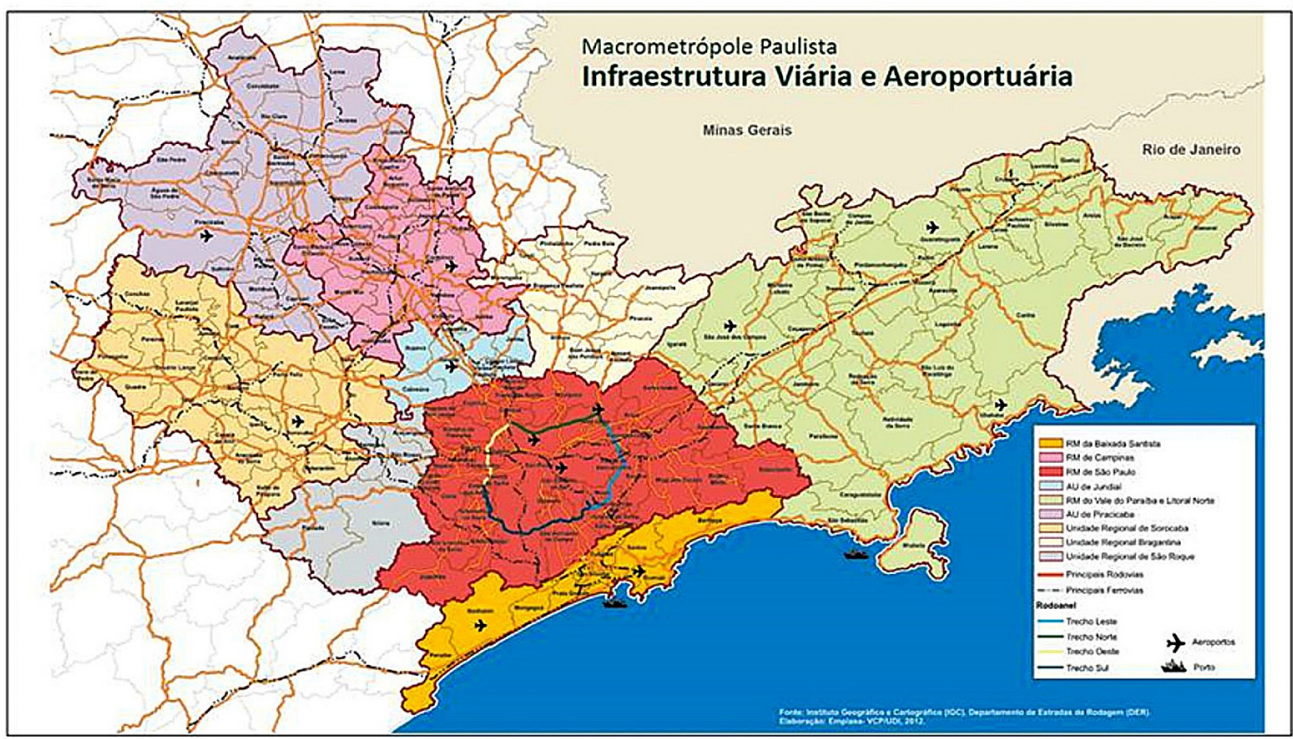

Fonte: Emplasa (2012). 
No período 2000/2010, observou-se uma mudança significativa nas tendências demográficas, com redução das taxas de crescimento populacional no Estado e na Macrometrópole, em função da diminuição das taxas de fecundidade e mortalidade. Também ocorreu redução das taxas de migração, em razão da recuperação de antigas áreas de emigração como Paraná e Minas Gerais e do estímulo resultante das políticas públicas de desconcentração econômica do país (Cunha e Baeninger, 2006).

Na última década, anualmente, a Região Metropolitana de São Paulo perdia em termos líquidos cerca de 30 mil pessoas, tendo o Censo 2010 registrado o menor crescimento populacional da região no período. Entre 2000 e 2010, a taxa de crescimento populacional da Macrometrópole foi de 0,97\%, a menor já apurada pelos Censos, e abaixo do patamar de 1,09\% observado em todo o Estado. Essas modificações tiveram reflexos sobre a estrutura etária da população. Houve redução da base da pirâmide etária, em razão da queda na fecundidade, e aumento da População em Idade Ativa (PIA) e do número de pessoas idosas.

Essas novas tendências e consequente perfil demográfico colocam grandes desafios para as políticas públicas. Além dos cuidados com educação, cultura e acesso a novas tecnologias, especialmente para os jovens, devem resultar em ações integradas para tornar mais confortável a vida da população idosa, que apresenta tendências de crescimento.

Apesar da concentração de riquezas, a Macrometrópole tem suas contradições .
De acordo com dados do Censo de 2010, 2,68 milhões de pessoas residiam em setores sub- normais (favelas, invasões e áreas de risco, entre outros) na Macrometrópole, equivalente a $98 \%$ das 2,7 milhões de pessoas vivendo nessa condição em todo o estado de São Paulo. Do total da população em aglomerados subnormais na MMP, 80,4\% estavam localizadas na RMSP, seguidos por $11 \%$ na RMBS. Trata-se de uma área de significativa heterogeneidade estrutural, com potencialidades diferenciadas de desenvolvimento econômico, social e urbano, com uma dívida social ainda elevada. É o que evidenciam as precárias condições de moradia de parcelas significativas da população, a crescente ocupação de áreas de risco e as deficientes infraestruturas urbana e social, entre outros problemas.

Mesmo que não seja totalmente conurbada, devido às barreiras físicas e à presença de áreas protegidas, a Macrometrópole é servida por um sistema viário e de transporte que propicia intensa articulação dos espaços urbanos, além da integração funcional das estruturas produtivas. Abriga novas formas de organização da produção numa rede urbana que se destaca pelo desempenho de funções complexas e diversificadas (multifuncionalidade) e que estabelecem relações econômicas com várias outras aglomerações urbanas (ver Mapa 3). A complementariedade socioespacial existente entre as RMs da Macrometrópole é inegável, uma vez que, como se mostrará a seguir, a mobilidade pendular é um importante indicador dessa condição. 


\section{Mapa 3 - Elementos funcionais de integração}

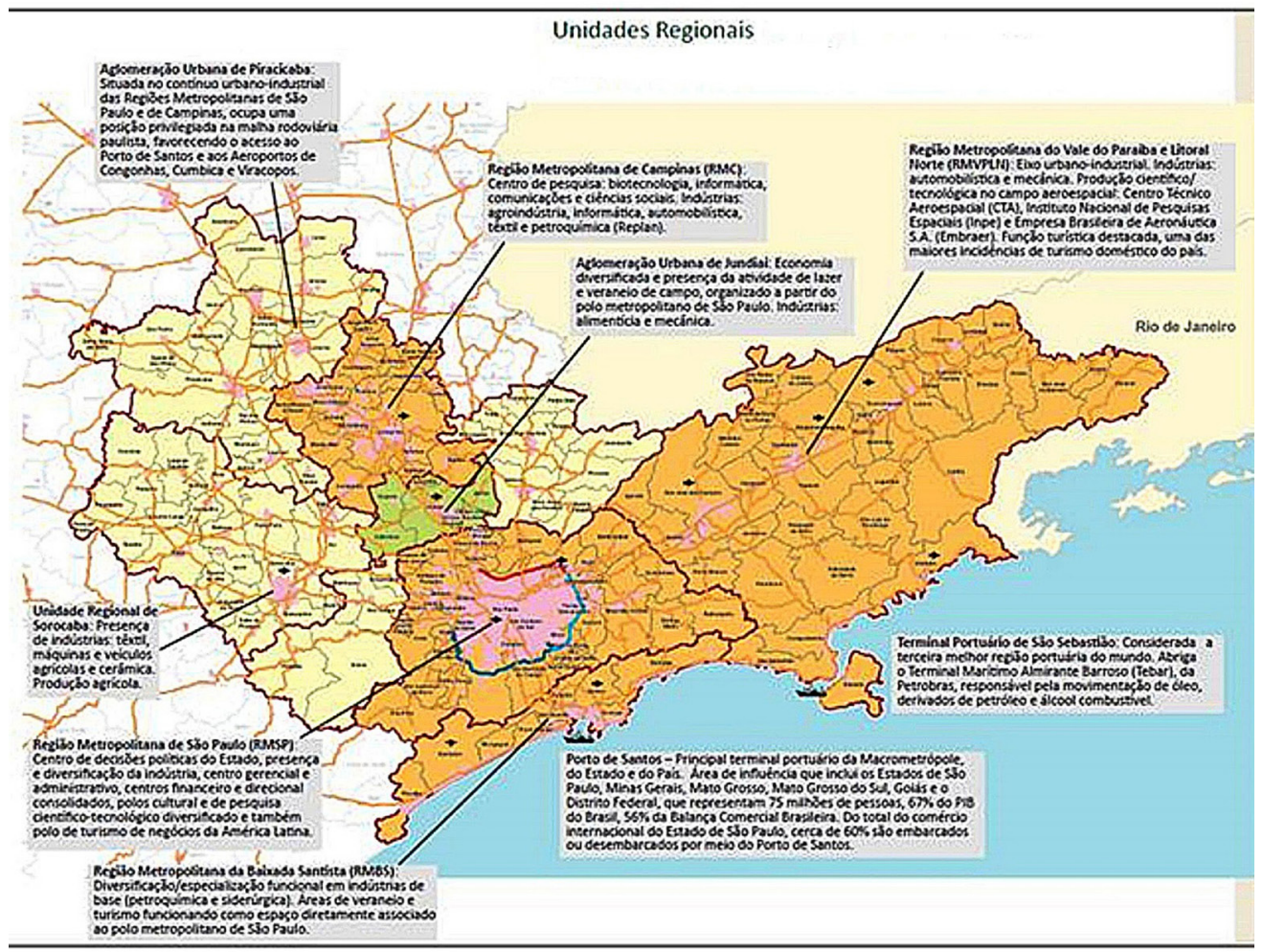

Fonte: Emplasa (2012). 


\section{Mobilidade pendular e a estruturação regional e do urbano: algumas considerações teóricas}

A mobilidade pendular coloca-se como um fenômeno característico das grandes aglomerações no atual momento da urbanização brasileira, quando se observa um aumento da complexidade socioespacial, em particular, no que diz respeito às localizações da população e atividades econômicas, sociais, etc. Na verdade, pode-se pensar que boa parte desse fenômeno estaria associada à valorização diferencial do espaço urbano que, no Brasil, tem tido ao longo das últimas décadas sua lógica e regulação fortemente orientadas pela inciativa privada sem a necessária intervenção pública, fato que acaba por prejudicar fortemente a população de mais baixa renda.

Reis Filho (2006, p. 44) alerta para um dos resultados desse processo, a chamada urbanização dispersa que pode ser compreendida em duas escalas:

[...] a primeira escala é a da área metropolitana, que vem mostrando uma dispersão crescente de núcleos ou polos, a presença crescente de vazios e uma frequente redução de densidades de ocupação, no todo e em partes importantes;

a segunda escala é a do tecido urbano

[...] o modo pelo qual se definem as relações entre espaços públicos e espaços privados (enquanto propriedade ou posse), entre espaços de uso privado e de uso coletivo, sejam estes de propriedade pública ou privada.
Esse modelo de ocupação do território alimenta um desencontro entre as áreas de trabalho e de moradia da população, aumentando a necessidade do deslocamento diário casa-trabalho. Para Aranha (2005), as desigualdades socioespaciais seriam a base explicativa da existência dessa mobilidade. Moura et al. (2005) se remetem a esses movimentos como um fenômeno não apenas que representa as desigualdades, mas também como um meio para a compreensão dos resultados da reestruturação do espaço metropolitano. Baeninger (2004) considera que a mobilidade pendular é em boa parte reflexo do processo de expansão urbana e suas tendências de concentrar as possibilidades de emprego com lógica distinta daquela com que se criam as possibilidades de moradia, gerando grandes dificuldades e descompassos entre as duas categorias de localização espacial. De qualquer modo, a possibilidade de mover-se no espaço intraurbano, incrementada pela melhoria ou maior oferta de transportes (mesmo que nem sempre em condições adequadas), implica para os indivíduos e/ou famílias em estratégias para a reprodução social (Cunha e Sobreira, 2008).

Esse "descompasso" entre espaço de moradia e trabalho já era fruto de preocupação na década de 1960, nos Estados Unidos, em estudos como os de Kain (1992), que apontavam para as relações entre a segregação habitacional dos trabalhadores afro-americanos e suas condições de emprego e renda, gerando o que foi conhecido como spatial mismatch hy pothesis. Se é verdade que no Brasil, e, em particular em São Paulo, as características e condições demográficas e urbanas são distintas daquelas encontradas nos EUA, particularmente 
dos anos 1960, não se pode negar que a lógica do "descompasso" entre os locais de moradia e das atividades econômicas está muito presente no nosso contexto, especialmente nas nossas metrópoles.

Ao pensar a mobilidade pendular também deve-se salientar sua relação com a migração, sobretudo a intrametropolitana (Cunha, 1994). A redistribuição espacial da população para atender as demandas habitacionais faz com que a migração tenha um papel relevante na geração de novos fluxos de pendulares. Nesse sentido, uma análise conjunta da mobilidade pendular a partir da condição migratória da população mostra-se de grande relevância, particularmente porque permite estabelecer a relação, já comentada, entre a solução habitacional e o acesso ao mercado de trabalho.

Ou seja, com a mobilidade residencial o indivíduo tende a incrementar, na maior parte das vezes, a sua mobilidade pendular, que a depender do grupo social que se está analisando, pode representar uma escolha (para os grupos mais abastados) ou uma imposição ou necessidade (no caso dos mais pobres). Certamente tal distinção faz grande diferença no momento de se pensar políticas públicas, particularmente, aquelas de caráter intersetorial que visem melhorar a vidas das pessoas.

Agora como pensar a mobilidade pendular desde uma perspectiva "extrarregional", ou seja, para ir além das fronteiras das aglomerações urbanas? ${ }^{3}$ Os estudos elaborados pela Emplasa (2012) e os desenvolvidos por Reis Filho (2006) contribuem sobremaneira nessa direção.

As novas formas de organização social nesse processo de urbanização metropolitana geram grande mobilidade e reforçam a necessidade da análise espacial compreender os movimentos do território, além dos limi- tes das divisões administrativas e conceituais da cidade, pois, como argumenta Reis Filho (2006, pp. 91-92), a organização do cotidiano passa a se dar em âmbito regional.

0 quadro que se configura é de reorganização da vida cotidiana. Uma parcela significativa da população passa ater a sua vida organizada em escala regional. As cidades deixam de ser as sedes da vida cotidiana, para se transformarem em polos de um sistema articulado em escala mais ampla, regional, no qual se desenvolve a vida cotidiana. Para uma porcentagem mais restrita da população, esse cotidiano se desenvolve também em escala interregional, como nos casos de alguns habitantes das Regiões Metropolitanas de São Paulo e Campinas, da Baixada Santista e do Vale do Paraíba, que se deslocam diariamente entre duas delas.

A regionalização do cotidiano implica necessariamente 0 aumento da mobilidade da população. 0 sistema, implantado no mercado de trabalho pelo setor industrial, terminou por induzir também a mobilidade nas áreas de comércio, nos serviços, no ensino e no lazer. As oportunidades oferecidas pelo comércio e pelos serviços já não são analisadas pelos empresários apenas em escala regional, pressupondo uma mobilidade constante dos habitantes dessas regiões.

Nesse sentido, a análise da evolução da mobilidade pendular na Macrometrópole Paulista é, sem dúvida nenhuma, um bom indicativo dos caminhos que o processo de estruturação do espaço urbano está tomando e, mais do que isso, aponta as possibilidades e as necessidades práticas que a intensificação desse processo traz para o planejamento territorial. 
Como já destacado, a constituição da Macrometrópole Paulista condiciona-se a uma série de transformações do tecido social das regiões que a compõem e de suas relações com outras localidades. Certamente, parte importante desse processo está na configuração do setor econômico e suas interfaces políticas e sociais. Um exemplo claro dessas transformações é o chamado processo de espraiamento econômico a partir da desconcentração industrial (Abdal, 2009). 0 fenômeno se dá pela desconcentração do principal polo industrial do país (a Região Metropolitana de São Paulo), a partir da década de 1970, e da reestruturação produtiva, a partir de 1990, que substitui a concentração dos empregos industriais pelo aumento da participação do setor de serviços na produção e no emprego.

A reorganização do setor produtivo, a busca por novos espaços de moradia, condições de vida e novos padrões sócio-ocupacionais e culturais fazem do estudo da Macrometrópole Paulista um caminho importante para a compreensão da complexa rede de relações interdependentes e complementares que exigem um olhar integrado do planejamento urbano.

Sobre o problema do desajuste espacial (spatial mismatch), Ihlanfeldt (1994, p. 226) sugere que as políticas públicas trabalhem a partir de duas categorias de intervenção:

[...] (1) políticas para reduzir as distâncias entre os locais residenciais das minorias e os locais de empregos disponíveis, e (2) políticas para melhorar a acessibilidade de trabalho das minorias, sem mudar tanto locais de trabalho ou residência. (Tradução nossa)

Obviamente em ambos os casos, os desafios são enormes e muito difíceis de serem alcançados em nossa sociedade, que tem no mercado a principal força indutora da localização tanto dos setores produtivos quanto do espaço habitável. Assim, estudos como o aqui desenvolvido teriam a qualidade de alertar e informar os formuladores dessas políticas para as características e tendências do fenômeno.

\section{A mobilidade pendular na Macrometrópole Paulista: evidências empíricas}

A mobilidade pendular ${ }^{4}$ motivada por traba- Iho ou estudo na Macrometrópole Paulista experimentou nos anos 2000, período de emergência desse grande aglomerado, um incremento de mais de $76 \%$, chegando a envolver quase três milhões de pessoas segundo o Censo de 2010.

Esse aumento do volume dos movimentos pendulares, mesmo em um contexto de significativa redução do crescimento demográfico de todas as suas RMs e aglomerações urbanas envolvidas, mostra que o fenômeno, embora seja fruto de um processo de crescimento, expansão e incremento da heterogeneidade socioespacial das regiões, não necessariamente depende de uma constância de crescimento demográfico.

Na verdade, a análise das regiões deixa muito claro que, em função da complementariedade, integração, continuidade e fluidez espacial que tende a caracterizar uma aglomeração urbana - em especial as de caráter metropolitano -, esse fenômeno pode adquirir certa autonomia em função de mudanças nas formas de uso e ocupação do solo urbano, 
Tabela 1 - Volume e peso relativo da mobilidade pendular de residentes sobre a População em Idade Ativa (PIA).

Regiões metropolitanas do estado de São Paulo, 2000 e 2010

\begin{tabular}{l|c|c|c|c}
\hline \multirow{2}{*}{ Regiões } & \multicolumn{2}{|c|}{ Volume dos movimentos pendulares } & \multicolumn{2}{c}{ Percentual da PIA } \\
\cline { 2 - 5 } & 2000 & 2010 & 2000 & 2010 \\
\hline RMC & 171.033 & 311.992 & 9,8 & 14,02 \\
RMSP & 1.108 .691 & 1.942 .001 & 8,4 & 12,65 \\
RMBS & 128.064 & 201.023 & 11,7 & 15,51 \\
RMVPLN & 84.621 & 149.597 & 5,9 & 8,50 \\
Outra Macro & 162.253 & 321.610 & 6,3 & 9,80 \\
\hline Total & 1.654 .662 & 2.926 .216 & 9,5 & 14,18 \\
\hline
\end{tabular}

Fonte: IBGE. Censo Demográfico de 2000 e 2010.

seja em termos demográficos ou mesmo econômicos. Em uma palavra, mais que uma consequência do crescimento demográfico, a mobilidade pendular reflete o "movimento" da metrópole fruto de rearranjos socioeconômicos e demográficos internos havidos que, como sabemos, dependem não apenas das ações privadas, mas também de intervenção pública, nesse último caso via regulação ou políticas específicas.

Não apenas chama a atenção o volume atingido pelos movimentos pendulares especialmente em 2010 (mais de 2,9 milhões de pessoas), mas também o expressivo impacto que estes representam sobre o volume da população em idade ativa (PIA). ${ }^{5}$ De fato, na região como um todo, mais de $14 \%$ desse grupo realiza esse tipo de deslocamento, uma vez que esse valor é menor na RMVPLN e nos outros municípios da Macrometrópole. Ou seja, o fenômeno da pendularidade não apenas ganha importância pelo fato de revelar a inter-relação entre subáreas e regiões, mas também pelo impacto que tem sobre a população residente de cada uma das unidades analisadas.

Dados analisados em estudo mais amplo (Nepo e Emplasa, 2013) mostram que tal impacto é ainda maior quando o olhar é direcionado ao nível municipal. Além disso, como se pode constatar na Tabela 2, o fenômeno é muito mais volumoso e intenso no interior das regiões metropolitanas constituintes da Macrometrópole. De fato, enquanto, em 2000, dos mais de 1,6 milhões de pessoas que faziam esse tipo de movimento, cerca de 85,5\% moviam-se no interior das regiões; essa parcela, embora em declínio, era ainda elevada em 2010, alcançando $81,5 \%$.

No entanto, como já se mencionou a maior novidade desse estudo é justamente analisar as características da mobilidade pendular segundo o destino e origem "externos", de maneira que se tenha melhor visão sobre as principais trocas existentes entre as RMs consideradas, as demais áreas da Macrometrópole e destas com o resto do estado ou país. 
Tabela 2 - Volume e variação da mobilidade pendular interna, externa e total. Regiões metropolitanas paulistas e municípios da Macrometrópole - 2000 e 2010

\begin{tabular}{l|r|r|r|r|r|r|r|r|r}
\hline \multirow{2}{*}{ Regiões } & \multicolumn{9}{|c|}{ Mobilidade Pendular } \\
\cline { 2 - 10 } & \multicolumn{3}{|c|}{2000} & \multicolumn{1}{c|}{2010} & \multicolumn{3}{c}{ Variação (\%) } \\
\cline { 2 - 10 } & \multicolumn{1}{|c|}{ Interno } & \multicolumn{1}{|c|}{ Externo } & \multicolumn{1}{c|}{ Total } & \multicolumn{1}{c|}{ Interno } & Externo & \multicolumn{1}{c}{ Total } & Interno & Externo & Total \\
\hline RMC & 134.796 & 35.543 & 171.033 & 241.077 & 70.915 & 311.992 & 78,85 & 99,52 & 82,42 \\
RMSP & 1.015 .221 & 89.162 & 1.108 .691 & 1.663 .374 & 278.627 & 1.942 .001 & 63,84 & 212,50 & 75,16 \\
RMBS & 102.380 & 25.451 & 128.064 & 160.346 & 40.677 & 201.023 & 56,62 & 59,82 & 56,97 \\
RMVPLN & 63.028 & 21.103 & 84.621 & 115.556 & 34.041 & 149.597 & 83,34 & 61,31 & 76,78 \\
Outras macro & 99.731 & 61.557 & 162.253 & 207.299 & 114.311 & 321.610 & 107,86 & 85,70 & 98,22 \\
\hline Total & 1.415 .156 & 232.816 & 1.654 .662 & 2.387 .652 & 538.571 & 2.926 .223 & 68,72 & 131,33 & 76,85 \\
\hline
\end{tabular}

Fonte: IBGE. Censo Demográfico de 2000 e 2010.

A Tabela 2 também mostra que mesmo sendo em volume bem inferior, a mobilidade pendular com destino "externo"6 apresenta um crescimento de mais de $131 \%$ na Macrometrópole, passando de 232 mil para cerca de 539 mil pessoas. Em termos das regiões específicas, o que se percebe é que o crescimento da pendularidade com destino externo foi muito mais importante justamente na RMSP, o que, de certa forma, seria esperado tendo em vista o "movimento" de interiorização e desconcentração produtiva, observadas desde essa área, sobretudo a partir dos anos 1980 (Negri et al., 1988). De qualquer forma em todas as demais regiões consideradas 0 aumento das trocas inter-regionais foi muito significativo, constituindo-se em um dado significativo da inter-relação progressiva dessas áreas.
Em termos dos destinos das pessoas que realizam o movimento pendular, Tabela 3, percebe-se que estes apresentaram mudanças quanto ao destino para trabalhar/estudar entre 2000 e 2010, com particularidades conforme a região metropolitana. Por exemplo, no caso da $\mathrm{RMC}$, a principal alteração verificada foi o aumento da importância dos pendulares que trabalham/estudam em outros municípios da Macrometrópole, ou outras unidades da Federação em detrimento do peso relativo dos movimentos pendulares para a RMSP e o interior de São Paulo. Pode-se dizer que tal comportamento espelha a intensificação do relacionamento e complementariedade dessa região com o resto do país. No entanto, percebe-se que o peso da RMVPLN e RMBS continua praticamente o mesmo, dando mostra de que a integração entre ambas as regiões mantêm-se. 
Tabela 3 - Destino "externo" da população residente que realiza movimento pendular. Regiões metropolitanas paulistas - 2000 e 2010

\begin{tabular}{|c|c|c|c|c|c|c|c|c|}
\hline \multirow{3}{*}{$\begin{array}{c}\text { Destino } \\
\text { dos pendulares }\end{array}$} & \multicolumn{8}{|c|}{ Região de residência dos pendulares } \\
\hline & \multicolumn{2}{|c|}{ RMC } & \multicolumn{2}{|c|}{ RMSP } & \multicolumn{2}{|c|}{ RMBS } & \multicolumn{2}{|c|}{ RMVPLN } \\
\hline & 2000 & 2010 & 2000 & 2010 & 2000 & 2010 & 2000 & 2010 \\
\hline RMC & - & - & 8,9 & 4,2 & 1,5 & 1,8 & 3,8 & 4,5 \\
\hline RMSP & 37,6 & 30,9 & - & - & 70,6 & 72,1 & 56,2 & 53,0 \\
\hline RMBS & 0,8 & 0,8 & 6,3 & 3,4 & - & - & 1,5 & 2,2 \\
\hline RMVPLN & 1,0 & 9 & 4,9 & 3,3 & 2,0 & 2,2 & - & - \\
\hline Outras macrometrópoles & 33,4 & 36,1 & 12,2 & 11,7 & 1,0 & 1,9 & 2,9 & 3,5 \\
\hline Interior SP & 21,3 & 14,2 & 53,1 & 17,3 & 20,2 & 5,8 & 14,2 & 5,7 \\
\hline Outros Estados & 2,8 & 17,1 & 14,7 & 60,0 & 4,6 & 16,2 & 21,3 & 31,0 \\
\hline Total & 35.536 & 70.895 & 89.163 & 278.604 & 25.404 & 40.668 & 21.104 & 34.041 \\
\hline
\end{tabular}

Fonte: IBGE. Censo Demográfico de 2000 e 2010.

No caso da RMSP, houve relevante aumento da importância daqueles que trabalham e estudam nos outros estados (1.178\%), ${ }^{7}$ em detrimento de grande redução do peso relativo do Interior/SP e pequenas reduções nas proporções das outras regiões, mesmo com 0 aumento do volume dessas.

Na RMBS a principal modificação ocorreu nos pendulares que se dirigiam para outros estados, cujo volume aumentou $460 \%$ e com a RMSP, que aumentou $63 \%$, e nesse caso, fica muito claro que a melhoria das condições de acessibilidade entre as duas regiões ocorridas nas últimas décadas apenas reforçou a complementariedade entre ambas. A participação relativa dos outros municípios do estado de São Paulo diminuiu.

Já na RMVPLN, as modificações foram menos acentuadas, mas com a redução da importância do interior do estado de São Paulo como destino dos pendulares e aumento de importância dos outros estados da federação. A pendularidade mais significativa nessa região é com a RMSP.

A Tabela 4 apresenta uma visão oposta, ou seja, a origem dos pendulares que trabaIham em cada uma das regiões consideradas. Assim como na tabela anterior, algumas mudanças ao longo do período analisado podem ser verificadas, sugerindo novamente o significativo nível de relacionamento ou complementariedade existente entre as regiões metropolitanas.

Em relação aos pendulares que se dirigem para a RM de Campinas, aqueles de origem em outras RMs mantiveram sua relação, em 2010, de proporção em relação àquela observada em 2000. Os pendulares residentes em "outros municípios da Macrometrópole" aumentaram o volume e sua participação relativa, passando de $35,4 \%$ para $39 \%$ daqueles que trabalham na RMC. 
Tabela 4 - Origem "externa" da população residente que realiza movimento pendular. Regiões metropolitanas paulistas - 2000 e 2010

\begin{tabular}{c|c|c|c|c|c|c|c|c|c}
\hline \multirow{2}{*}{$\begin{array}{c}\text { Regiões de } \\
\text { destino }\end{array}$} & \multicolumn{10}{|c|}{ Regiões de origem dos Pendulares } \\
\cline { 2 - 10 } & Censo & RMC & RMSP & RMBS & RMVPLN & $\begin{array}{c}\text { Outras } \\
\text { Macrometrópoles }\end{array}$ & $\begin{array}{c}\text { Interior } \\
\text { SP }\end{array}$ & $\begin{array}{c}\text { Outros } \\
\text { Estados }\end{array}$ & Total \\
\hline \multirow{2}{*}{ RMC } & 2000 & - & 19,2 & 0,9 & 2,0 & 35,4 & 25,0 & 17,5 & 41.249 \\
& 2010 & - & 15,0 & 0,9 & 2,0 & 39,1 & 21,3 & 21,7 & 77.688 \\
\hline \multirow{2}{*}{ RMSP } & 2000 & 7,7 & - & 10,3 & 6,8 & 17,6 & 14,8 & 42,8 & 174.718 \\
& 2010 & 8,1 & - & 10,8 & 6,7 & 19,6 & 11,5 & 43,3 & 270.992 \\
\hline \multirow{2}{*}{ RMBS } & 2000 & 2,3 & 46,4 & - & 2,6 & 3,3 & 18,2 & 27,2 & 12.136 \\
& 2010 & 2,3 & 40,1 & - & 3,2 & 3,0 & 15,4 & 35,9 & 23.877 \\
\hline \multirow{2}{*}{ RMVPLN } & 2000 & 3,7 & 35,9 & 4,1 & - & 4,1 & 8,7 & 44,1 & 12.105 \\
& 2010 & 2,7 & 37,5 & 3,7 & - & 4,1 & 6,7 & 45,2 & 24.423 \\
\hline
\end{tabular}

Fonte: IBGE. Censo Demográfico de 2000 e 2010.

A RM de São Paulo foi a que menos sofreu alterações com relação à origem dos pendulares entre 2000 e 2010: as proporções permaneceram semelhantes, com aproximadamente $25 \%$ dos pendulares originados nas RMs do Estado, mas com modificações em relação ao interior do estado de São Paulo, que reduziu a participação (de 14,8\% para 11,5\%), e outros estados e outros municípios da Macrometrópole que registraram leve aumento nos pendulares.

Pequenas alterações também foram verificadas nas proporções apresentadas pela RM do Vale do Paraíba e Litoral Norte. Nessa área destaca-se como origem a RM de São Paulo, da qual saem aproximadamente $37 \%$ dos pendu- lares, assim como os pendulares de outros es- tados, que representam $45,2 \%$ do total. Já na RM da Baixa Santista o destaque fica para a redução da proporção dos pendulares da RM de São Paulo (46,3\%, em 2000, contra 40,1\% em 2010), assim como aumento dos pendulares de outros estados $(27,2 \%$, em 2000 , contra $35,8 \%$ em 2010).

Outra informação que demonstra a intensidade da circulação das pessoas por motivo de trabalho é o fato de esses deslocamentos pendulares ocorrerem, de maneira geral, diariamente. Considerando os destinos daqueles que se deslocam diariamente para trabalhar em outros municípios (Tabela 5), nota-se que quando se trata de deslocamento para município da mesma região metropolitana mais de $90 \%$ realizam seus deslocamentos nesses termos. Observa-se também que no caso da mobilidade pendular ser feita para outra região, ainda assim boa parte desses movimentos tem caráter diário. Como se percebe na tabela mencionada, isso acontece principalmente no caso do destino ser a RMSP. Para a RMC, isso também é verdade, especialmente para os deslocamentos para "outras regiões", provavelmente 
Tabela 5 - Proporção de movimentos pendulares por motivo de trabalho realizados diariamente. Regiões metropolitanas paulistas - 2010

\begin{tabular}{l|c|c|c}
\hline \multirow{2}{*}{ Regiões Origem } & \multicolumn{2}{|c}{ Regiões Destino } \\
\cline { 2 - 4 } & Própria & RMSP & Outras \\
\hline RM de São Paulo & 96,2 & - & 63,0 \\
RM de Campinas & 97,4 & 61,5 & 74,0 \\
RM de Baixada Santista & 96,3 & 66,4 & 34,0 \\
RM Vale do Paraíba e Litoral Norte & 91,2 & 50,3 & 27,0 \\
\hline
\end{tabular}

Fonte: IBGE. Censo Demográfico 2010.

pelo fato da maioria delas ser também de caráter de mais curta distância. Já para a RMBS e RMVPLN, os percentuais de movimentos diários para outras regiões distintas da RMSP são bem mais baixos, fato que talvez espelhe as especificidades dessas regiões, sobretudo em termos das atividades econômicas aí desenvolvidas como a portuária, petroquímica e aeroespacial.

De maneira geral, até aqui se buscou mostrar que os movimentos pendulares na Macrometrópole atingem contingentes expressivos de sua população em idade ativa. Além disso, o volume e intensidade desse fenômeno não apenas revelam distintos momentos de cada uma das regiões consideradas em termos da integração e complementariedade entre seus municípios, mas também níveis distintos de interação entre elas, reforçando a ideia da constituição de uma grande região que extravasa os limites predeterminados das RMs oficialmente constituídas.
Contudo para avançar um pouco mais na natureza dessa interação seria importante considerar outras características da mobilidade pendular de forma a se ter maior clareza sobre "quem" realiza esse tipo de movimento e, de maneira indireta, "quais" os motivos que poderiam explicar tais intercâmbios populacionais.

Nesse sentido, a próxima seção realiza um diagnóstico sobre algumas características das pessoas que realizam esse tipo de mobilidade e residem na Macrometrópole Paulista. As características escolhidas foram sexo, idade, nível educacional e atividade econômica de inserção, uma vez que a análise será realizada, em primeiro lugar, de modo a mostrar as características do conjunto dos movimentos pendulares e, em segundo lugar, sua diferenciação segundo o destino dos que realizam esse movimento, ou seja, se dentro ou fora de suas regiões de residência. 


\section{Quem são os que realizam a pendularidade? ${ }^{8}$}

Em primeiro lugar pode-se dizer que o perfil dos que realizam a mobilidade pendular é muito mais masculino que a população em geral. De fato, o Gráfico 1 mostra predominância de homens entre aqueles que realizam esse tipo de movimento, visto que o padrão é semelhante para as quatro regiões metropolitanas: em média, mais de $60 \%$ desses pendulares são homens. A menor diferença é observada na RM de São Paulo, onde os homens representam 61,4\% dos pendulares; nas RMs de Campinas e Baixada Santista os valores são iguais $(64,4 \%)$, e a maior diferença observada se dá na RM do Vale do Paraíba e Litoral Norte, região onde os homens representam 70,1\% dos pendulares.
Também no que se refere à composição etária, a população que realiza movimento pendular mostra significativa seletividade em relação à população total residente nas regiões: uma concentração maior nas idades altamente produtivas (20 a 55 anos). Como fica claro na Tabela 6, em consonância com o que já se conhece sobre a população como um todo, a RM da Baixada Santista é a que apresenta a PIA mais envelhecida, com menor proporção no grupo "25 a 39 anos" e maior no grupo " 56 anos e mais", que representa aproximadamente $4 \%$ mais população do que as outras RMs. 0 reflexo dessa PIA mais envelhecida culmina também num grupo de pendulares maior na faixa "56 anos e mais" em relação ao observado nas outras RMs.

0 padrão etário da pendularidade para as RMs paulistas tem uma curvatura ascendente a

Gráfico 1 - Proporção da população total, com 15 anos ou mais e dos pendulares segundo sexo. Regiões metropolitanas paulistas - 2010

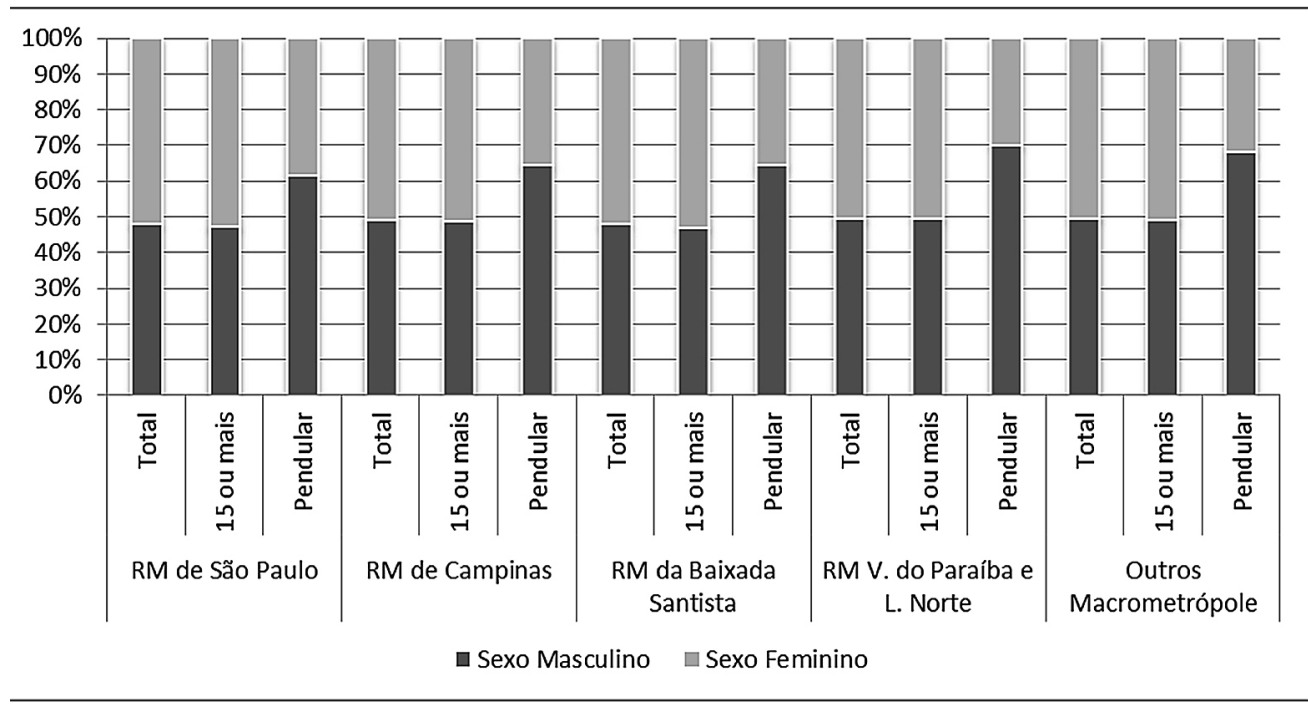

Fonte: IBGE. Censo Demográfico de 2010. 
Tabela 6 - PIA e pendulares segundo distribuição por grupos etários.

Regiões metropolitanas paulistas -2010

\begin{tabular}{|c|c|c|c|c|c|c|c|}
\hline \multirow[b]{2}{*}{ Regiões } & \multirow[b]{2}{*}{ População } & \multicolumn{5}{|c|}{ Faixa etária } & \multirow[b]{2}{*}{ Total } \\
\hline & & $\begin{array}{c}15 \text { a } 17 \\
\text { anos }\end{array}$ & $\begin{array}{c}18 \text { a } 24 \\
\text { anos }\end{array}$ & $\begin{array}{c}25 \text { a } 39 \\
\text { anos }\end{array}$ & $\begin{array}{c}40 \text { a } 55 \\
\text { anos }\end{array}$ & $\begin{array}{c}56 \text { anos } \\
\text { e mais }\end{array}$ & \\
\hline \multirow{2}{*}{ RM de São Paulo } & PIA & 6,1 & 15,5 & 33,7 & 26,5 & 18,3 & 15.363.202 \\
\hline & Pendular & 1,3 & 16,6 & 45,5 & 30,0 & 6,6 & 1.690 .923 \\
\hline \multirow{2}{*}{ RM de Campinas } & PIA & 6,0 & 15,5 & 33,1 & 26,9 & 18,5 & 2.224 .662 \\
\hline & Pendular & 1,2 & 16,7 & 45,9 & 30,3 & 5,9 & 287.548 \\
\hline \multirow{2}{*}{ RM da Baixada Santista } & PIA & 6,1 & 14,4 & 30,9 & 26,5 & 22,1 & 1.297.130 \\
\hline & Pendular & 0,8 & 14,3 & 44,4 & 32,3 & 8,1 & 185.247 \\
\hline \multirow{2}{*}{ RM V. do Paraíba e L. Norte } & PIA & 6,5 & 15,4 & 32,5 & 26,9 & 18,8 & 1.761 .629 \\
\hline & Pendular & 1,0 & 15,5 & 45,5 & 31,3 & 6,7 & 129.670 \\
\hline \multirow{2}{*}{ Outros Macrometrópoles } & PIA & 6,2 & 15,5 & 32,2 & 26,5 & 19,6 & 3.189 .705 \\
\hline & Pendular & 1,3 & 16,7 & 45,5 & 30,2 & 6,3 & 287.627 \\
\hline
\end{tabular}

Fonte: IBGE. Censo Demográfico de 2010.

partir dos 18 anos de idade, uma vez que quase metade dos pendulares se encontra entre $25 \mathrm{e}$ 39 anos de idade. A faixa etária entre 40 e 55 anos também se mostra importante, onde se encontram mais de um quarto dos pendulares; nessa faixa ocorre a inflexão da curva com a proporção de pendulares se reduzindo drasticamente a partir dos 56 anos de idade.

Os dados observados com relação à distribuição etária dos pendulares nos ajuda a pensar a respeito da importância da escolaridade enquanto característica central para compreender o fenômeno, já que os que realizam esse tipo de movimento são sistematicamente mais escolarizados que os demais residentes componentes da PIA. Por isso é possível compreender o porquê de apenas $1 \%$ dos pendulares terem entre 15 e 17 anos.

Os dados da Tabela 7 apresentam as diferenças existentes entre os pendulares e a PIA das RMs paulistas em termos de escolaridade. ${ }^{9}$ Apesar dos padrões apresentados serem relativamente próximos entre as regiões, pode-se destacar alguns pontos fundamentais: enquanto a maior parte da PIA (próximo a $45 \%$ ) apresenta como escolaridade o ensino fundamental, a maior parte dos pendulares (próximo de 40\%) apresenta o ensino médio. A escolaridade aparece, portanto, como fator chave nessa discussão, pois afeta diretamente a renda e possibilidade de inserção produtiva dos indivíduos e, portanto, está associada às possibilidades de locomoção cotidiana nas metrópoles.

Um fato merece atenção, a RM do Vale do Paraíba e Litoral Norte é onde se observa a população residente pendular mais escolarizada: 31,3\% possuem graduação ou pós-graduação. Esse resultado, associado à constatação já realizada de que nessa região a mobilidade pendular externa tem maior peso relativo, parece reforçar ainda mais a relação entre esse tipo de movimento e a condição socioeconômica dos envolvidos, particularmente quando as distâncias a serem percorridas são maiores e, portanto, mais onerosas. 
Tabela 7 - Proporção dos maiores de 15 anos e dos pendulares segundo escolaridade e região de residência. Regiões metropolitanas paulistas - 2010

\begin{tabular}{l|c|c|c|c|c|c}
\hline \multirow{2}{*}{ Regiões } & \multirow{2}{*}{ População } & \multicolumn{5}{|c}{ Nível de ensino } \\
\cline { 3 - 7 } & & $\begin{array}{c}\text { Ensino } \\
\text { Fundamental }\end{array}$ & $\begin{array}{c}\text { Ensino } \\
\text { Médio }\end{array}$ & Graduação & $\begin{array}{c}\text { Pós- } \\
\text { graduação }\end{array}$ & \multirow{2}{*}{ Outro } \\
\hline \multirow{2}{*}{ RMSP } & PIA & 45,1 & 33,7 & 16,4 & 3,2 & 1,4 \\
& Pendular & 34,0 & 39,6 & 21,4 & 4,2 & 0,8 \\
\hline \multirow{2}{*}{ RMC } & PIA & 47,8 & 33,2 & 14,5 & 3,1 & 3,4 \\
& Pendular & 33,3 & 37,9 & 21,8 & 6,4 & 0,6 \\
\hline \multirow{2}{*}{ RMBS } & PIA & 45,4 & 36,3 & 15,1 & 2,1 & 1,0 \\
& Pendular & 30,5 & 42,2 & 22,6 & 4,3 & 0,5 \\
\hline \multirow{2}{*}{ RMVPLN } & PIA & 45,9 & 37,5 & 13,2 & 2,6 & 0,9 \\
& Pendular & 26,4 & 42,0 & 25,3 & 6,0 & 0,3 \\
\hline Outras & PIA & 51,5 & 32,8 & 12,4 & 2,1 & 1,2 \\
Macrometrópoles & Pendular & 34,6 & 37,9 & 21,7 & 5,3 & 0,5 \\
\hline
\end{tabular}

Fonte: IBGE. Censo Demográfico de 2010.

Por outro lado, na RM de São Paulo, $74,4 \%$ dos pendulares apresentam escolaridade até o ensino médio, sendo a região com pendulares de menor nível educacional. Esses diferenciais estão ligados ao tipo de emprego desses indivíduos e certamente ao fato de que a RMSP é o grande centro de ofertas de empregos e oportunidades do país; ou seja, muitos dos mais escolarizados não teriam necessidade de buscar alternativas fora da região.

A Tabela 8 apresenta a divisão dos pendulares e da PEA a partir da natureza de trabalho ${ }^{10}$ que realizam, ou seja, se "manual" ou "não manual". Nesse sentido, os dados salientam que existem diferenciais importantes.

Tabela 8 - PEA e pendulares segundo distribuição por tipos de emprego.

Regiões metropolitanas paulistas - 2010

\begin{tabular}{l|c|c|c|c}
\hline \multirow{2}{*}{ Regiões } & \multirow{2}{*}{ População } & \multicolumn{3}{|c}{ Tipo de emprego } \\
\cline { 3 - 5 } & & Manual & Não Manual & Outro \\
\hline \multirow{2}{*}{ RM de São Paulo } & PEA & 63,9 & 30,0 & 6,1 \\
& Pendular & 64,0 & 29,0 & 7,0 \\
\hline \multirow{2}{*}{ RM de Campinas } & PEA & 66,6 & 24,9 & 8,5 \\
& Pendular & 60,7 & 31,8 & 7,5 \\
\hline \multirow{2}{*}{ RM da Baixada Santista } & PEA & 68,5 & 21,9 & 9,6 \\
& Pendular & 62,4 & 27,9 & 9,7 \\
\hline \multirow{2}{*}{ RM V. do Paraíba e L. Norte } & PEA & 69,1 & 21,2 & 9,7 \\
\hline
\end{tabular}

Fonte: IBGE. Censo Demográfico de 2010. 
No caso da RM de São Paulo, inexistem diferenciais entre os pendulares e a PEA, resultado de uma maior integração e interdependência existente na região, e como já dito provavelmente em função do tamanho e complexidade de seu mercado de trabalho. Já as RMs capitaneadas por Campinas e Santos apresentam diferenças relevantes com relação à RM de São Paulo, assim como a RMVPLN que, uma vez mais, apresenta a maior diferença entre pendulares e PEA.

Pode-se pensar que tais diferenças, num sentido mais amplo, estariam ligadas a outras características dessas regiões, como por exemplo, os setores de atividades predominantes em cada uma. Quando se considera o setor de atividade $^{11}$ dos trabalhadores pertencentes à $P E A$ em geral e aqueles que realizam movimento pendular (Tabela 9), pode-se notar algumas áreas específicas onde estes últimos se sobressaem, assim como outras áreas onde eles têm pouca diferença; tal comportamento é também diferenciado segundo a região metropolitana considerada.

No caso da RM de São Paulo, por exemplo, a grande diferença entre PEA e pendulares está nos setores de "Indústria de transformação" e "Comércio". Nesse caso, os pendulares apresentam maior proporção na primeira, e pouca empregabilidade no caso da segunda. Em relação aos outros setores pouca variação é observada. Na RM de Campinas a mesma característica é observada, entretanto, com relação aos "Serviços domésticos", há uma proporção menor dos pendulares em relação à PEA, diferentemente do caso de São Paulo, onde a proporção é semelhante.

Na RM da Baixada Santista a característica é exatamente igual à RM de Campinas, com uma pequena distinção com relação ao ramo de "serviços". Nele os pendulares levam ligeira vantagem em relação ao total da PEA, situação que não se observa nas outras regiões.

Tabela 9 - População Economicamente Ativa e pessoas que realizam movimentos pendulares segundo áreas de ocupação. Regiões metropolitanas paulistas - 2010

\begin{tabular}{|c|c|c|c|c|c|c|c|c|c|}
\hline \multirow[b]{2}{*}{ Regiões } & \multirow[b]{2}{*}{ População } & \multicolumn{8}{|c|}{ CNAE - Atividades econômicas } \\
\hline & & Serviços & $\begin{array}{c}\text { Energia e } \\
\text { saneamento }\end{array}$ & $\begin{array}{c}\text { Indústria de } \\
\text { transformação }\end{array}$ & Comércio & $\begin{array}{l}\text { Agropecuária } \\
\text { e extrativismo }\end{array}$ & Construção & $\begin{array}{c}\text { Serviços } \\
\text { domésticos }\end{array}$ & Outro \\
\hline \multirow{2}{*}{ RMSP } & PEA & 44,9 & 0,8 & 13,9 & 17,0 & 0,7 & 6,1 & 6,8 & 9,8 \\
\hline & Pendular & 43,0 & 0,8 & 18,4 & 14,2 & 0,6 & 6,9 & 6,0 & 10,2 \\
\hline \multirow{2}{*}{$\mathrm{RMC}$} & PEA & 36,8 & 1,0 & 19,3 & 16,1 & 2,4 & 7,1 & 6,7 & 10,6 \\
\hline & Pendular & 36,7 & 0,8 & 23,7 & 13,4 & 2,1 & 7,1 & 4,8 & 11,4 \\
\hline \multirow{2}{*}{ RMBS } & PEA & 47,7 & 1,1 & 7,6 & 18,3 & 1,3 & 9,1 & 8,6 & 6,2 \\
\hline & Pendular & 51,4 & 1,0 & 11,4 & 13,5 & 1,5 & 8,4 & 6,6 & 6,2 \\
\hline \multirow{2}{*}{ RMVPLN } & PEA & 39,4 & 1,1 & 14,6 & 16,8 & 4,2 & 9,7 & 8,5 & 5,6 \\
\hline & Pendular & 44,6 & 1,3 & 21,2 & 12,9 & 2,9 & 9,5 & 2,5 & 5,1 \\
\hline Outras & PEA & 32,9 & 1,0 & 22,5 & 16,4 & 5,5 & 7,9 & 7,0 & 6,8 \\
\hline Macrometrópoles & Pendular & 38,8 & 0,9 & 26,8 & 13,1 & 3,5 & 7,1 & 3,3 & 6,6 \\
\hline
\end{tabular}

Fonte: IBGE. Censo Demográfico de 2010. 
Já a RM do Vale do Paraíba e Litoral Norte novamente se diferencia significativamente das demais. Essa região é a que apresenta a maior diferença entre a PEA total e as pessoas que realizam movimento pendular. Nesse caso, os pendulares apresentam proporção maior no setor de "Serviços" (como na RMBS), maior participação na "Indústria de Transformação" e menor no "Comércio" (como RMSP, RMC e RMBS). Também registra menor participação nos "Serviços Domésticos" (como RMC e RMBS) sendo o seu principal diferencial a menor participação dos pendulares na "Agropecuária e Extrativismo", que, para as outras RMs, os dados entre pendulares e PEA se mostraram semelhantes.

\section{As especificidades segundo o local de destino dos movimentos pendulares}

Tendo em vista as peculiaridades desse tipo de mobilidade espacial, particularmente em função de seu caráter regular - e, como já mostrado, em geral diário - seria de se esperar que a seletividade apresentada pelos indivíduos "pendulares" se acentuasse à medida que as distâncias se incrementassem. Nesse sentido, considera-se importante analisar também as características desse movimento discriminado por seu destino "interno" (dentro da mesma RMs ou aglomeração) ou "externo" (fora da RM ou aglomeração). Esse dado é organizado na Tabela 10.

A partir dessa tabela se percebe que, de fato, os movimentos pendulares que se dirigem para áreas externas às respectivas regiões de residência tendem a ser mais seletivos, especialmente com relação a sexo, idade e educação.

Os dados mostram que a predominância de homens se exacerba no caso dos movimentos pendulares externos, já que esses tendem a representar, em média, mais de $70 \%$ dos deslocamentos. Tal comportamento se repete para todas as RMs e também para os "outros municípios da Macrometrópole". Quanto à idade, aqueles que se dirigem para fora das regiões de residência são sensivelmente mais envelhecidos (maior concentração no grupo 40 a 55 anos) que os que se movimentam internamente, muito embora ainda prevaleça o fato de que a grande maioria permaneça abaixo dos 55 anos.

Talvez o que mais chame a atenção seja a composição da pendularidade por nível educacional. Nesse caso, é marcante a diferença entre os pendulares externos e internos, uma vez que os primeiros apresentam, em geral, muito maior participação nas categorias "graduação" e "pós-graduação". Vale notar, no entanto, que esse comportamento não é registrado na Região Metropolitana de São Paulo, o que talvez seja explicado, como já salientado, pelo fato de que as maiores oportunidades para profissionais qualificados estejam justamente concentradas nessa região não requerendo, portanto, deslocamentos mais intensos de pessoas com esse tipo de perfil. Por outro lado, nas demais RMs do interior é visível a seletividade em favor dos mais capacitados em termos educacionais. 


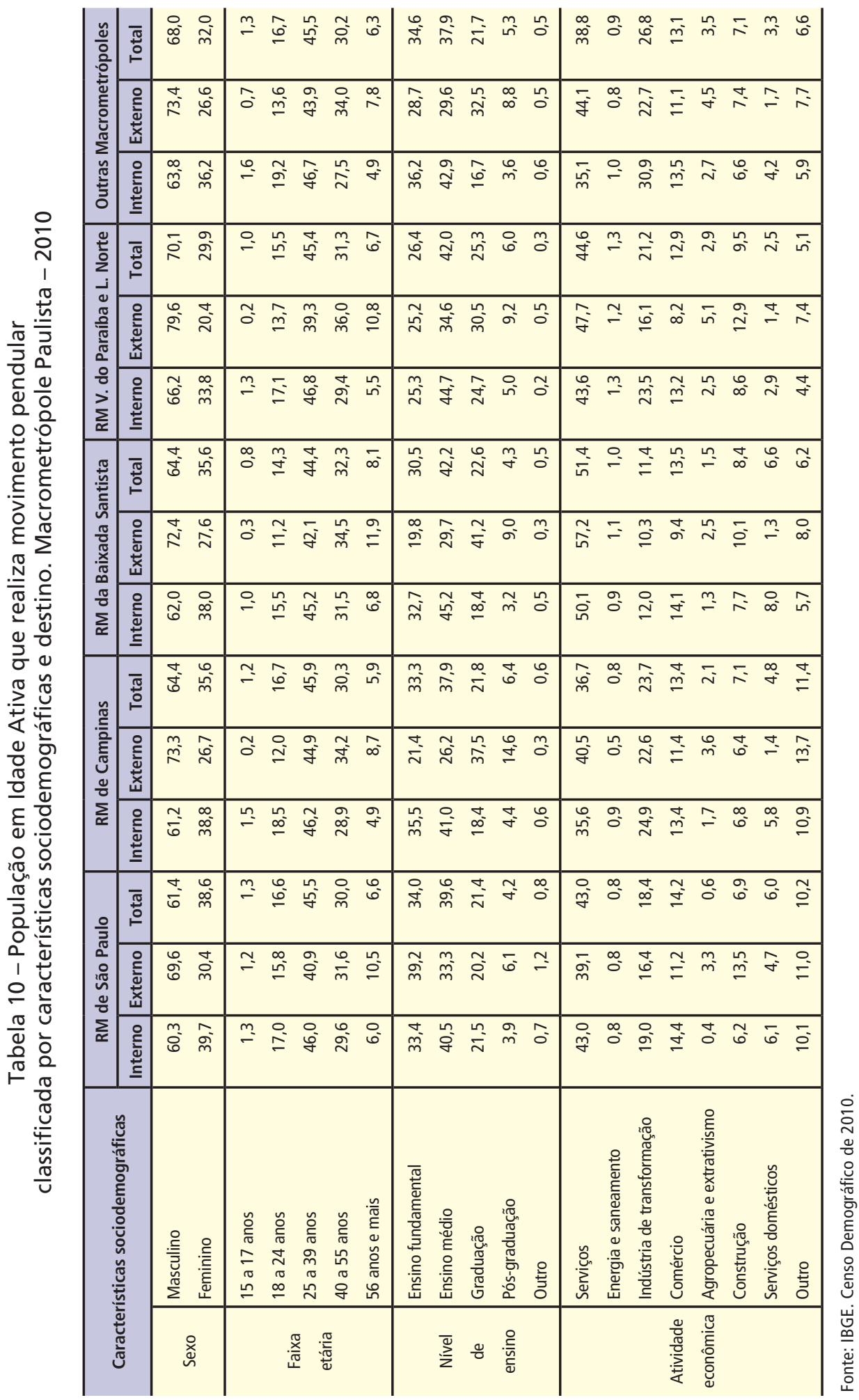


Finalmente, em termos do tipo de atividade exercida pela PEA, não são observadas grandes diferenças entre pessoas que se movem para fora ou no interior de suas regiões de residência. Mesmo considerando que se percebem algumas pequenas diferenças, como no caso da RMBS onde os "internos" são mais concentrados na atividade de "comércio", ou na RMVPLN onde se registra maior concentração destes na "Indústria de Transformação", a verdade é que tais discrepâncias são muito menos acentuadas que nas variáveis anteriormente analisadas.

Em suma, os dados sugerem que, mais que buscar novas atividades, as pessoas que se movem para fora de suas regiões de residência são aquelas mais qualificadas e mais experientes (levando em conta a idade) que muito provavelmente formam parte de um grupo de profissionais que respondem às demandas das empresas que possuem maior flexibilidade locacional, ou mesmo optem por residirem em regiões mais tranquilas e longe das aglomerações dos grandes centros, em particular o município de São Paulo.

\section{Considerações finais}

A análise realizada tratou de mostrar que a mobilidade pendular, se não totalmente, ao menos parcialmente revela ou reflete de maneira eloquente o grau de complementariedade e/ou integração existente entre distintos territórios.

No caso da Macrometrópole Paulista, os dados aqui analisados dão conta de que a emergência dessa que seria a maior aglomeração urbana do país, é claramente percebida a partir da observação não apenas das tendências, mas também das características do fenômeno que aqui se chamou de "pendularidade".

De fato, além de ter crescido de maneira impressionante ao longo da década de 2000, atingindo mais de 530 mil pessoas, as características dos indivíduos envolvidos na mobilidade pendular que se estabelem entre as RMs que compõem a Macrometrópole são também sugestivas no que diz respeito aos fatores condicionantes desse processo, ou seja, a desconcentração produtiva e suas consequências socioespaciais como é o caso das novas formas de urbanização e localização da população.

Dessa análise pode-se perceber que os fluxos estabelecidos apontam na direção da intensificação das relações entre as RMs, especialmente da RMSP com as demais, e a movimentação de pessoas cujo perfil predominantemente masculino, de pessoas adultas jovens, melhor qualificadas e empregadas na indústria de transformação, sugere que esse tipo de mobilidade não apenas espelha a já mencionada desconcentração econômica, como também novas preferências locacionais, especialmente por parte das pessoas de mais alta renda.

Como já observava Santos (1996), esse crescimento continuamente acelerado da complementariedade regional é uma tendência associada à especialização do sistema produtivo e, consequentemente, altera a organização do trabalho, a vida social, o espaço:

As especializações do território, do ponto de vista da produção material, assim criadas, são a raiz das complementariedades regionais: há uma nova geografia regional que se desenha, na base da nova divisão territorial do trabalho que se impõe. 
Essas complementariedades fazem com que, em consequência, se criem necessidades de circulação, que vão tornar-se frenéticas, dentro do território brasileiro, conforme avança o capitalismo; uma especialização territorial que é tanto mais complexa quanto maior o número de produtos e a diversidade de sua produção. Estamos diante de novo patamar, quanto à divisão territorial do trabalho. Essa se dá de forma mais profunda e esse aprofundamento leva a mais circulação e mais movimento em função da complementariedade necessária. Mais circulação e mais movimento permitem de novo 0 aprofundamento da divisão territorial do trabalho, o que, por sua vez, cria mais especialização do território. (Santos, 1996, p. 41)
Seja como for, esse fenômeno não deixa dúvidas que, de fato, está ocorrendo uma ampliação das relações regionais em um âmbito espacial cada vez maior, e que tal processo tem implicações significativas não apenas do ponto de vista do planejamento estadual, mas também de cada região ou município envolvidos.

Assim, mais que um simples estudo de um fenômeno social, a análise da mobilidade pendular pode fornecer uma radiografia, ainda que aproximada, do grau de permeabilidade, interação, contiguidade ou complementariedade existentes entre os subespaços, elementos centrais para se ter em conta quando realmente se pensa em um planejamento regional realista e não excludente.

\section{José Marcos Pinto da Cunha}

Universidade Estadual de Campinas, Departamento de Demografia, Instituto de Filosofia e Ciências Humanas, Núcleo de Estudos Populacionais. Campinas,/SP, Brasil.

zemarcos@nepo.unicamp.br

\section{Sergio Stoco}

Universidade Estadual de Campinas, bolsista CNPq de pós-doutorado do Núcleo de Estudos de População - Nepo. Campinas/SP, Brasil.

brestoco@outlook.com

\section{Ednelson Mariano Dota}

Pontifícia Universidade Católica de Campinas, Faculdade de Geografia. Campinas/SP, Brasil.

eddota@yahoo.com.br

\section{Rovena Negreiros}

Empresa Paulista de Planejamento Metropolitano - Emplasa. São Paulo/SP, Brasil. rnegreiros@sp.gov.br

\section{Zoraide Amarante Itapura de Miranda}

Empresa Paulista de Planejamento Metropolitano - Emplasa. São Paulo/SP, Brasil. zoraideamarante@gmail.com 


\section{Notas}

(*) Este trabalho é resultado da pesquisa "O fenômeno da mobilidade pendular na Macrometrópole do Estado de São Paulo: uma visão a partir das quatro Regiões Metropolitanas oficiais", desenvolvida pelo Nepo/Unicamp para a Emplasa.

(1) Na verdade até agora não se cunhou um termo tão eloquente quanto o seu similar em inglês commuting, o mesmo acontece com o substantivo que designa aqueles indivíduos que realizam esse tipo de movimento (commuter).

(2) Dados da Pesquisa Origem Destino (Artesp, 2006).

(3) Na verdade, até mesmo o consenso de que os limites municipais já não dão conta mais da dinâmica e diversidades socioespacial nas grandes aglomerações urbanas é relativamente recente. Esse estudo mostra que já é necessário superar inclusive esse limite espacial.

(4) Um esclarecimento faz-se necessário. De forma a tornar comparável os dados dos Censos 2000 e 2010, neste último caso foram agregados numa só categoria os pendulares por trabalho e por estudo, uma vez que, ao contrário do que ocorreu em 2000, foram captados de forma separada. Apenas como detalhe técnico registra-se que para tal agrupamento foi necessário controlar a dupla contagem daqueles que fizeram tanto pendularidade por estudo quanto por trabalho. Para o IBGE, a indivíduo "pendular" seria aquele maior de 10 anos de idade que estuda ou trabalha (nesse caso, na semana anterior ao Censo) em município distinto ao de residência. Neste estudo foram considerados apenas os movimentos pendulares realizados pela população maior de 15 anos, com declaração de município de trabalho ou estudo. Esse corte etário foi escolhido por se tratar do grupo populacional conhecido como a "População em Idade Ativa" (PIA), além de, no caso da educação, ter maior probabilidade de estar no ensino médio ou superior que na maior parte dos casos justifica a mobilidade pendular por motivos educacionais.

(5) O uso da proporção da PIA que realiza movimento pendular pode ser entendido como um indicador não apenas de impacto, mas também de intensidade do fenômeno na medida em que relaciona o evento (a pendularidade) como a população que supostamente o estaria gerando (a população em idade ativa residente). Uma vez que a captação do fenômeno, segundo o IBGE, refere-se à última semana antes do Censo, o uso da PIA recenseada como denominador é bastante adequado.

(6) Considera-se como destino externo do movimento para trabalho ou estudo qualquer município fora de região de referência.

(7) Esse dado merece um esclarecimento. Realmente chamou muito a atenção que, em 2010, o volume de pendularidade da RMSP para outros estados tenha aumentado tanto. Embora tal resultado esteja de acordo com dados divulgados pelo IBGE, ainda assim parece estranho que um volume tão grande de pessoas realize esse tipo de deslocamento para estados tão distantes, como é o caso do estado da Bahia com o qual se registrou mais de 56 mil pessoas. Uma das possíveis explicações para tal comportamento talvez seja o fato de que, sendo boa parte desses movimentos devido ao estudo (informação possível de se obter no Censo 2010), os jovens que lá estudavam seriam recenseados como residentes nos municípios de seus pais ou responsáveis, sendo, portanto, "contados" como pendulares ("moravam" na RMSP e estudavam fora). Realmente a identificação da população residente no caso de estudantes nem sempre é tranquila e pode ter impacto na quantificação da pendularidade. 
(8) Nessa seção foram considerados apenas os movimentos pendulares captados a partir da informação relativa ao "município de trabalho" do Censo Demográfico de 2010.

(9) Os níveis de ensino apresentados para escolaridade da população são resultantes do maior nível de estudo completo ou incompleto disponibilizado nas informações do censo 2010.

(10) A distinção entre ocupações manuais e não manuais refere-se à classificação de ocupações para pesquisas domiciliares, considerando que os "não manuais" correspondem aos códigos classificados no censo 2010 como dirigentes, profissionais das ciências e intelectuais.

(11) Os grupos de atividade econômica utilizados correspondem às seções e divisões do Código Nacional de Atividade Econômica, apresentadas pelo censo 2010.

\section{Referências}

ABDAL, A. (2009). São Paulo, desenvolvimento e espaço: a formação da macrometropole paulista. São Paulo, Papagaio.

ARANHA, V. (2005). Mobilidade pendular na metrópole paulista. São Paulo em Perspectiva, v. 19, n. 4. Disponível em: http://www.scielo.br/scielo.php?script=sci_arttext\&pid=S0102-88392005000400006. Acesso em: 10/3/2013.

BAENINGER, R. (2004). Interiorização da migração em São Paulo: novas territorialidades e novos desafios teóricos. Disponível em: http://www.abep.nepo.unicamp.br/site_eventos_abep/PDF/ ABEP2004_545.pdf. Acesso em: 10/3/2013.

CANO, W. (1998). Raízes da concentração industrial em São Paulo. Unicamp.

COSTA, M. A. C. (1975). Urbanização e migração urbana no Brasil. Rio de Janeiro, IPEA/INPES.

CUNHA, J. M. P. da (1994). Mobilidade populacional e expansão urbana: o caso da Região Metropolitana de São Paulo. Tese de doutorado. Campinas, Universidade Estadual de Campinas.

CUNHA, J. M. P. da e BAENINGER, R. (2006). Las migraciones internas en el Brasil contemporáneo. Notas de población. CEPAL, n. 82.

CUNHA, J. M. P. da e SOBREIRA, D. P. (2008). A metrópole e seus deslocamentos populacionais cotidianos: o caso da mobilidade pendular na Região Metropolitana de Campinas em 2000. Revista Latinoamericana de Población, ano 1, n. 2, pp. 99-125.

EMPLASA (1992). Dinâmica da Macrometrópole: Análise Introdutória. São Paulo, Empresa Metropolitana de Planejamento da Grande São Paulo.

(2011). Rede urbana e regionalização do estado de São Paulo. São Paulo, Empresa Metropolitana de Planejamento da Grande São Paulo.

(2012). Macrometrópole PaulistaSão Paulo. São Paulo, Empresa Metropolitana de Planejamento da Grande São Paulo. Disponível em: http://www.emplasa.sp.gov.br/emplasa/. Acesso em: $17 / 1 / 2013$.

EMPLASA; FSEADE/SEP (2010). Estudos Emplasa: série território. São Paulo, Empresa Metropolitana de Planejamento da Grande São Paulo/Cebrap. 
IBGE (2009). Produto Interno Bruto dos Municípios. Brasília, Instituto Brasileiro de Geografia e Estatística em parceria com os órgãos estaduais de Estatística, Secretarias Estaduais de Governo e Superintendência da Zona Franca de Manaus - Suframa.

IHLANFELDT, K. (1994). The Spatial Mismatch Between Jobs and Residential Locations Within Urban Areas. Cityscape. Georgia State University.

JARDIM, A. de P. (2007). Algumas reflexões sobre o estudo das migrações pendulares. Disponível em: http://www.abep.nepo.unicamp.br/docs/anais/outros/5EncNacSobreMigracao/mesa_04_alg_ ref_sob.pdf. Acesso em: 10/3/2013.

KAIN, J. F. (1992). The spatial mismatch hypothesis: three decades later. Housing Policy Debate, v. 3, Issue 2. Universidade de Harvard.

LOBO, C. F. F.; CARDOSO, L. e MATO, R. E. S. (2009). Mobilidade pendular e centralidade espacial: considerações sobre o caso da região metropolitana de Belo Horizonte. Instituto de Geociências. Disponível em: (http://www.cbtu.gov.br/monografia/2009/trabalhos/artigos/ planejamento/4_130_AC.pdf). Acesso em: 10/3/2013.

MEYER, R. e GROSTEIN, M. (2012). A nova etapa do percurso metropolitano de São Paulo (dinâmicas urbanas, as novas territorialidade e dimensão urbano-ambiental da metrópole de São Paulo. Projeto Temático. São Paulo, Fapesp/Lume/FAUUSP.

MOURA, R. (2009). Arranjos urbano-regionais no Brasil. Tese de doutorado. Curitiba, Universidade Federal do Paraná.

MOURA, R.; CASTELLO BRANCO, M. L. G. e FIRKOWSKI, O. L. C. de F. (2005). Movimento pendular e perspectivas de pesquisas em aglomerados urbanos. São Paulo Perspectiva, v. 19, n. 4. Disponível em: http://www.scielo.br/scielo.php?pid=S0102-88392005000400008\&script=sci_arttext. Acesso em: 10/3/2013.

NEGRI, B. (1996). Concentração e desconcentração industrial em São Paulo (1980-1990). Tese de doutorado. Campinas, Universidade Estadual de Campinas.

NEGRI, B.; GONÇALVES, M. F. e CANO, W. (1988). “O processo de interiorização do desenvolvimento e da urbanização no Estado de São Paulo (1920-1980)". In: CANO. W. (org.). A interiorização do desenvolvimento econômico no Estado de São Paulo (1920-1980). São Paulo, Seade.

NEPO, EMPLASA (2013). O fenômeno da mobilidade pendular na Macrometrópole do Estado de São Paulo: uma visão a partir das quatro Regiões Metropolitanas oficiais. Relatório de Pesquisa, Campinas. Disponível em: http://www.emplasa.sp.gov.br/emplasa/. Acesso em: 17/1/2013.

OLIVEIRA, L. A. P. e OLIVEIRA, A. T. R. (orgs.) (2011). Reflexões sobre os deslocamentos populacionais no Brasil. Rio de Janeiro, IBGE.

PACHECO, C. A. (1998). Fragmentação da nação. Campinas, Unicamp/IE.

PASTERNACK, S. e BÓGUS, L. M. M. (2005). Migração na metrópole. São Paulo Perspectiva, v. 19, n. 4. Disponível em: http://www.scielo.br/scielo.php?script=sci_arttext\&pid=S0102-88392005000400002\&lng=en\&nr m=iso\&tlng=pt. Acesso em: 10/3/2013.

PEREIRA, R. H. M. (2008). Processos socioespaciais, reestruturação urbana e deslocamentos pendulares na região metropolitana de Campinas. Dissertação de mestrado. Campinas, Universidade Estadual de Campinas. 
REIS FILHO, N. G. (2006). Notas sobre urbanizaçao dispersa e novas formas de tecido urbano. São Paulo, Via das Artes.

REIS, N. G. e TANAKA, M. S. (org.) (2007). Brasil, estudos sobre a dispersão urbana. São Paulo, FAUUSP/ Fapesp, pp. 7-28.

RIBEIRO, L. C. Q. et al. (2012). Níveis de integração dos municípios brasileiros em RMs, RIDEs e AUs à dinâmica da metropolização. Rio de Janeiro, Observatório das Metrópoles/UFRJ.

SANTOS, M. (1996). A urbanização brasileira. São Paulo, Hucitec.

SOBREIRA, D. P. (2007). A metrópole e seus deslocamentos populacionais cotidianos: o caso do deslocamento pendular na Região Metropolitana de Campinas. Dissertação de mestrado. Campinas, Universidade Estadual de Campinas.

SOUZA, M. A. (1978). Cidades médias e desenvolvimento industrial: uma proposta de descentralização metropolitana. São Paulo, Secretaria de Economia e Planejamento. Coordenadoria de Ação Regional-SEP.

SPÓSITO, M. E. B. (2009). "Novas formas de produção do espaço urbano no Estado de São Paulo". In: REIS FILHO, N. G. (org.). Sobre dispersão urbana. São Paulo, Via das Artes.

Texto recebido em 18/mar/2013

Texto aprovado em 29/abr/2013 
